\title{
Conduction velocity and fibre diameter of the median and ulnar nerves of the baboon
}

\author{
J. G. MCLEOD AND SHIRLEY H. WRAY \\ From the Institute of Neurology, Queen Square, London
}

Nerve conduction studies are extensively employed in the diagnosis of disorders of the peripheral nerves in man. Since most of the previous experimental work has been performed on cats and other small animals, it was of particular interest to study conduction in the peripheral nerves of primates; this has received little attention until a recent study by Eccles, Phillips, and Chien-Ping (1966). The present investigation was undertaken in order to obtain values for conduction velocity in the motor and sensory fibres of the median and ulnar nerves, and to relate these to their respective fibre calibre spectrum. The relationship between conduction velocity and fibre diameter appears to have been little investigated in primates, and although the factor relating these two variables obtained by Hursh (1939) in the cat has been widely accepted, it does not necessarily apply to all species of warm-blooded animals (Cragg and Thomas, 1964) nor to all sizes of myelinated fibres (Boyd, 1965; Bessou and Perl, 1966).

\section{METHODS}

Experiments were performed on 11 adult female baboons (Papio anubis) weighing 9.5-14.5 kg.

OPERATIVE TECHNIQUES Operations were performed under strict aseptic conditions. Anaesthesia was induced with a combination of phencyclidine hydrochloride $(2 \mathrm{mg} . / \mathrm{kg}$.) and promazine hydrochloride $(1 \mathrm{mg} . / \mathrm{kg}$.) given by intramuscular injection, and was maintained throughout the operation with a mixture of nitrous oxide and oxygen ( 2 volumes : 1 volume) administered through an endotracheal tube. When necessary, pentobarbitone sodium, 50-100 mg. intraperitoneally, was given to facilitate muscular relaxation and to maintain the depth of anaesthesia. A continuous intravenous infusion of $5 \%$ dextrose in normal saline was given throughout the operation. The rectal temperature was maintained above $35.5^{\circ} \mathrm{C}$. by means of radiant heat.

In six animals, dorsal root ganglia were excised from segments C5 to T2 in order to produce de-afferentation of the distal forelimb. A subperiosteal hemilaminectomy was performed on the left side from the level of $\mathrm{C} 4$ to $\mathrm{T} 2$. In order to excise the ganglion, each dorsal root was cut at its zone of entry into the spinal cord and the ganglion carefully dissected away from the ventral root with the aid of an operating microscope. The dorsal root was then cut distal to the ganglion. At the completion of each operation a black silk marker suture was tied round the T3 root and its position confirmed at necropsy. In four animals (baboons $M, N, T$, and $V$ ), ventral root sections were performed in order to produce de-efferentation of the distal forelimb. In these animals the ventral roots from C5 and T2 inclusive were cut extradurally, the site of the section being proximal to the overlying ganglion. At the end of each operation the muscle layers and skin were sutured and the animals allowed to recover. All the animals recovered satisfactorily from the operation.

In a de-afferented limb there is some risk of trauma to the insensitive extremity; this was prevented by fitting a well padded and slightly angulated full-arm plaster of Paris splint within a few days of the operation, the splint $\stackrel{9}{9}$ being removed to permit conduction velocity measure- $\triangle \mathrm{Q} \Omega$ ments and re-applied afterwards. Contracture of theo paralysed forelimb muscles following ventral root section was prevented by manipulating the arm through a full range of movement under anaesthesia.

ELECTROPHYSIOLOGICAL TECHNIQUES Electrophysiological studies were carried out on the median and ulnar nerves of both forearms of baboons which had been previously anaesthetised with phencyclidine and promazine. A period of at least 21 days was allowed for Wallerian degeneration to occur before these studies were commenced and they were then performed on several different occasions on each animal until it was finally killed. The animals from which dorsal root ganglia had been excised were killed at intervals which ranged from 37 to 67 days after operation and those in which ventral roots had been sectioned were killed at intervals which ranged from $\mathbf{4 5}$ to $\mathbf{9 0}$ days after operation. During the electrical recordings, the bodies of the animals were wrapped in cotton wool and the temperature of the forearm was maintained at $37-39^{\circ} \mathrm{C}$. by direct heat from a covered hot-water bottle under the limb and by radiant heat from an electric lamp. The temperature of the limb was measured with a thermistor inserted deeply into the forearm flexor group of muscles, $2-3 \mathrm{~cm}$. below the elbow.

In the median nerve motor conduction velocity was determined in the fastest conducting fibres to the abductor pollicis brevis muscle (Fig. 1a); in the ulnar nerve the motor fibres to the first dorsal interosseous muscle and the abductor digiti minimi muscle were studied. Using a supramaximal stimulus to the nerve, the 
compound muscle action potential was recorded through a steel needle electrode inserted into the muscle belly with reference to a more remote needle electrode in the distal part of the second or fifth digit. The nerves were stimulated at four to six sites between wrist and elbow; the distances between these sites were measured on the surface of the skin to the nearest $0 \cdot 1 \mathrm{~cm}$. The stimulating cathode was a steel needle inserted through the skin to lie close to the nerve and the anode was a metal clip placed proximally in the upper arm. Great care was taken in positioning the stimulating cathode to minimize the excitation of other nerves in the forearm. An earth electrode was positioned between the stimulating and recording electrodes. When the recording electrodes were correctly placed, the initial deflection of the muscle action potential was a negative (upward) deflection and the action potential had a similar configuration with stimulation at different sites. At each site of stimulation the latency was measured to the onset of the negative deflection of the action potential and plotted against the conduction distance.

The conduction velocity for each nerve was calculated from the slope of the straight line drawn through the points to give the best fit by eye.

Conduction in afferent fibres was determined in all animals by recording nerve action potentials from the median and ulnar nerves in the forearm following supramaximal stimulation at the wrist (Fig. 1b). The stimulating cathode was a subcutaneous steel needle electrode inserted close to the nerve at the wrist; the anode was a metal clip placed distally in the palm of the hand. Recordings were made through steel needles inserted through the skin to lie close to the nerve. Recording needles with an interpolar distance of approximately $2.0 \mathrm{~cm}$. were placed in pairs at four sites between wrist and elbow, and the distance between the recording sites was subsequently measured on the skin to the nearest $0 \cdot 1 \mathrm{~cm}$. At each recording site, the latency was measured to the onset of the initial negative deflection of the action potential, and plotted against the conduction distance. The conduction velocity of the volley in the fastest conducting fibres of each nerve was then calculated from the slope of the line drawn through the points to give the best fit by eye.

The stimulus was a brief condensor discharge (time constant 50 or $100 \mu \mathrm{sec}$.) derived from a thyratron stimulator and delivered through a $1: 1$ isolating transformer. The recording electrodes were connected to the input of an R-C coupled preamplifier and the responses were displayed on the upper beam of a cathode ray oscilloscope, the time scale being displayed on the lower beam. Superimposed photographic records were made on $35 \mathrm{~mm}$. film; for analysis of records the film was placed in an enlarger and measurements were made on the projected traces.

HISTOLOGICAL TECHNIQUES After completion of the electrophysiological studies the animals were killed at intervals which ranged from 37 to 90 days after operation (see previous section). In all animals $2 \mathrm{~cm}$. lengths of nerve were removed immediately after death from the median and ulnar nerves above the wrist. In the case of the median nerves, the level of section was $23 \mathrm{~mm}$. proximal to the flexor retinaculum and in the case of the ulnar nerves, $24 \mathrm{~mm}$. proximal to the centre of the pisiform bone. In the six animals from which ganglia had been excised the distal stumps of the corresponding sensory roots were removed, and in the four animals on which ventral root section had been performed, the distal stumps of the appropriate ventral roots were taken for examination. In some animals sections of the spinal cord were also removed for subsequent histological examination.

The lengths of nerve were splinted on cards and fixed immediately in Flemming's solution, embedded in paraffin wax and cut transversely at $5 \mu$. Sections were stained by Kultschitsky's haematoxylin and differentiated in $0.25 \%$ potassium permanganate and Pal's solution (Gutmann and Sanders, 1943).

A photomicrograph $(\times 1,000)$ was taken of each nerve section and the prints fitted together so that a picture of the whole cross section was available for subsequent measuring of nerve fibres. A count of the total number of myelinated fibres and a measurement of their external diameter was then performed on selected median and ulnar nerves using a mechanical counter and a graduated perspex cursor (Espir and Harding, 1961; Wray, 1967). In the remaining median and ulnar nerves, total fibre counts only were made with reference to a survey photograph, at a magnification $\times 60$.

The estimated degree of shrinkage in the diameter of fibres resulting from the technique was not thought to exceed 10\% (Hursh, 1939; Sanders, 1948) and there is no reason to suppose that shrinkage affected large and small fibres differently (Sherrington, 1894; Donaldson and Hoke, 1905; Duncan, 1934; Gutmann and Sanders, 1943). Errors of measurement introduced by sampling were excluded since all the fibres over $2 \mu$ in each fascicle in the nerve were counted for construction of the histogram and the external diameters of all fibres greater than $10 \mu$ were measured for correlation of fibre diameter and nerve conduction. Diameter measurements were not made on fibres when folds in the myelin sheath suggested that the section was in the immediate vicinity of the node of Ranvier (Williams and Landon, 1963).

\section{RESULTS}

CONDUCTION VELOCITY IN CONTROL NERVES Motor conduction velocity was determined in the median and ulnar nerves on the intact (right) side on two or three separate occasions in each of the 11 animals (Fig. 1a). Typical responses from which conduction times were measured for baboon $M$. are shown in Fig. 2a, and the graph from which the conduction velocity was calculated for the same animal is shown in Figure 3. The results are summarized in Table $I$, from which it can be seen that the motor conduction velocity in the fastest fibres of the median nerve ranged from $60 \mathrm{~m}$. $/ \mathrm{sec}$. to $84 \mathrm{~m}$. $/ \mathrm{sec}$. (mean $72.4 \pm 7.5 \mathrm{~m}$. $/ \mathrm{sec}$.) and in the fastest fibres of the ulnar nerve it ranged from $69 \mathrm{~m}$. $/ \mathrm{sec}$. to $86 \mathrm{~m}$. $/ \mathrm{sec}$. 

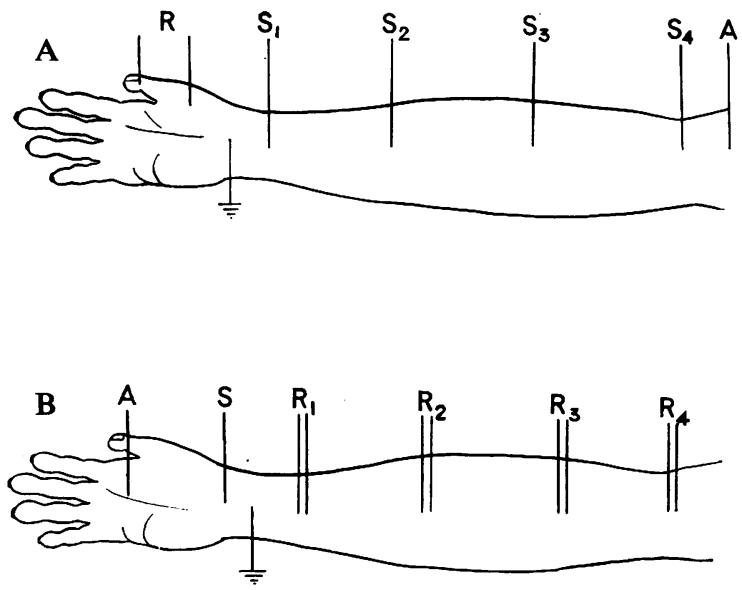

FIG. 1. Positions of electrodes on the forelimb of the baboon. Diagram A shows the position of the recording electrodes, $R$, for recording the muscle action potential of the abductor pollicis brevis muscle when stimulating the median nerve subcutaneously at cathode sites $S 1, S 2, S 3$, and $S 4$. The position of the anode is represented by $A$.

Diagram B shows the position of the pairs of electrodes $R 1$, $R 2, R 3$, and $R 4$, inserted subcutaneously for recording the compound action potential of the median nerve when stimulating with a needle cathode, $S$, at the wrist. The position of the anode is represented by $A$.
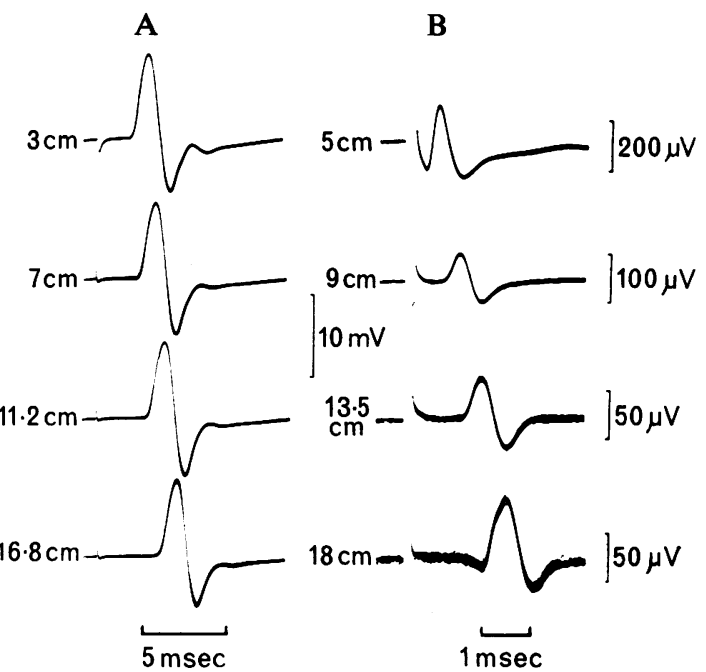

FIG. 2. Records of compound action potentials obtained from $\mathrm{A}$, first dorsal interosseous muscle on stimulating the intact ulnar nerves at different sites, and $\mathrm{B}$, from different sites on the ulnar nerve when stimulating the same nerve at the wrist. Baboon $M$. Electrode arrangements as in Figure 1. Distances between stimulating cathode and recording electrodes are indicated at the left of each record.
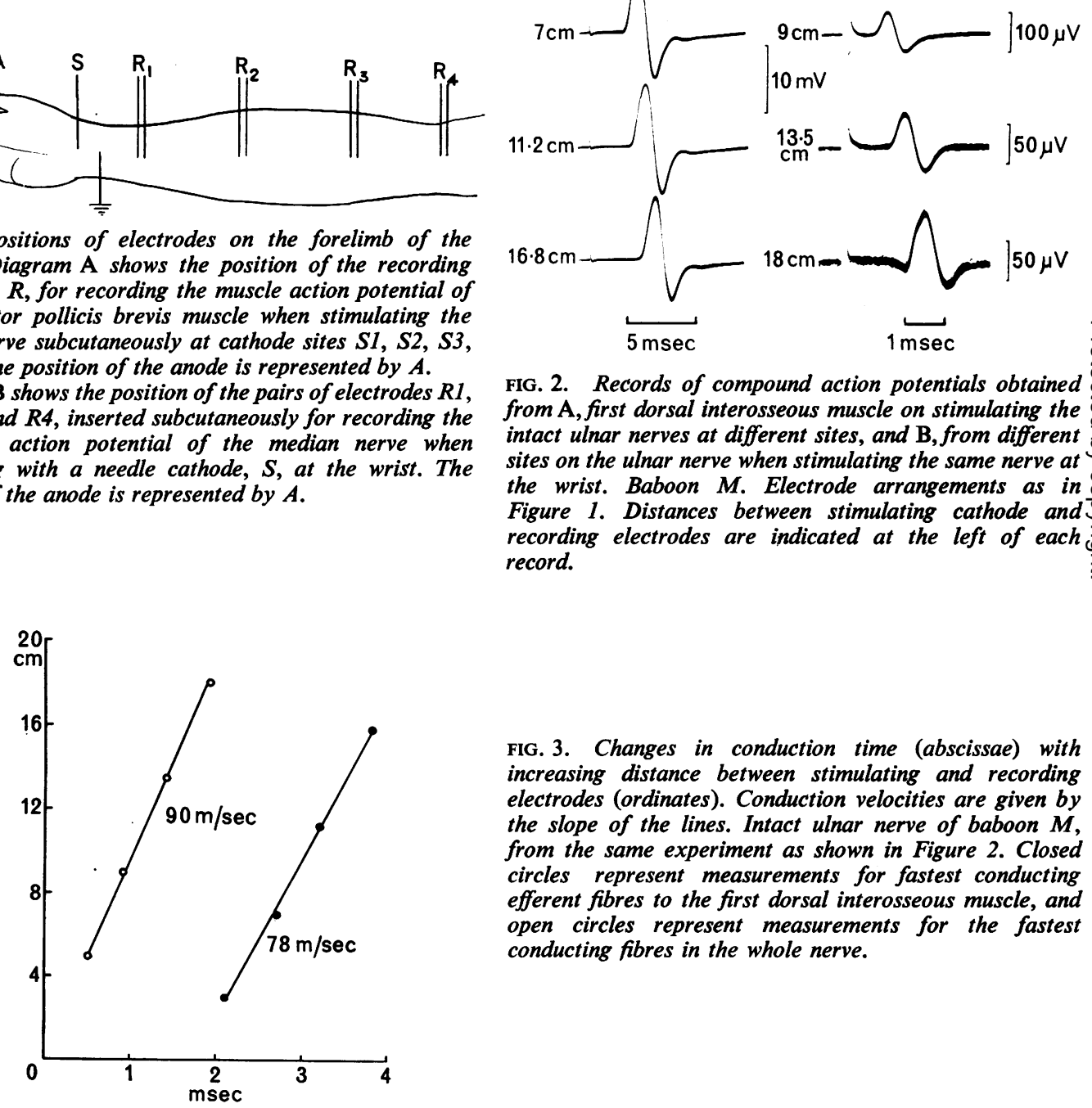

FIG. 3. Changes in conduction time (abscissae) with increasing distance between stimulating and recording electrodes (ordinates). Conduction velocities are given by the slope of the lines. Intact ulnar nerve of baboon $M$, from the same experiment as shown in Figure 2. Closed circles represent measurements for fastest conducting efferent fibres to the first dorsal interosseous muscle, and open circles represent measurements for the fastest conducting fibres in the whole nerve. 
(mean $76.5 \pm 5.1 \mathrm{~m} . / \mathrm{sec}$.). This difference is significant $(P<0.05)$. In the ulnar nerve there was no significant difference between the conduction velocities of the fastest motor fibres supplying abductor digiti minimi and those supplying the first dorsal interosseus muscle.

In six animals conduction velocity was determined for the fastest conducting fibres contributing to the nerve action potential recorded from four sites in the forearm on stimulating the median and ulnar nerves at the wrist (Fig. 1b). Typical responses from which conduction times were measured are shown in Fig. 2b, and the graph from which the conduction velocity was calculated for the same animal is shown in Figure 3. The results are summarized in Table I, from which it can be seen that the conduction velocity in the fastest fibres of the median nerve ranged from $76 \mathrm{~m} . / \mathrm{sec}$. to $103 \mathrm{~m}$. $/ \mathrm{sec}$. (mean $91.3 \pm 7.2 \mathrm{~m}$. $/ \mathrm{sec}$.) and in the fastest fibres of the ulnar nerve the velocity ranged from $90 \mathrm{~m}$./sec. to $111 \mathrm{~m}$. $/ \mathrm{sec}$. (mean $98.1 \pm 5.7 \mathrm{~m}$. $/ \mathrm{sec}$.). The difference between these two means is significant $(P<0.05)$.

\section{TABLE I}

CONDUCTION VELOCITY OF FASTEST CONDUCTING FIBRES OF INTACT MEDIAN AND ULNAR NERVES

$\begin{array}{ll}\text { Motor Fibres } & \text { Fastest Conducting } \\ & \text { Fibres in Whole } \\ \text { Nerve }\end{array}$

\begin{tabular}{lll}
\hline Median nerve & $60-84 \mathrm{~m} . / \mathrm{sec} .(23)$ & $76-103 \mathrm{~m} . / \mathrm{sec} .(12)$ \\
& $(72 \cdot 4 \pm 7.5)$ & $(91 \cdot 3 \pm 7 \cdot 2)$ \\
Ulnar nerve & $69-86 \mathrm{~m} / \mathrm{sec} .(26)$ & $90-111 \mathrm{~m} . / \mathrm{sec} .(12)$ \\
& $(76.5 \pm 5 \cdot 1)^{1}$ & $(98 \cdot 1 \pm 5 \cdot 7)$
\end{tabular}

${ }^{1}$ Conduction velocity to abductor digiti minimi muscle $=\mathbf{7 7 \cdot 2} \pm \mathbf{5 \cdot 4}$ $\mathrm{m}$./sec. (11).

Conduction velocity to first dorsal interosseous muscle $=\mathbf{7 6 . 0} \pm \mathbf{4 \cdot 7}$ $\mathrm{m} . / \mathrm{sec}$. (15).

Mean figures are given with standard deviations.

Numbers in brackets after range of conduction velocities refer to number of observations.

It is concluded from these results that the fastest conducting fibres in the median and ulnar nerves of the baboon are afferent fibres, and that their conduction velocities were $20-25 \%$ higher than those of the fastest efferent fibres in the same nerves. The conduction velocities of both efferent and afferent fibres were slightly higher in the ulnar than in the median nerve.

CONDUCTION VELOCITY AFTER VENTRAL ROOT SECTION Conduction velocity was determined in the afferent fibres of the median and ulnar nerves of four animals (baboons $M, N, V$, and $T$ ) after section of the ventral roots on the left side from segmental levels C5 to T2 inclusive. No muscular contraction was observed in the hand on electrical stimulation of these nerves at the wrist. Further confirmation that the ventral root section was complete was the subsequent histological demonstration of complete Wallerian degeneration in the ventral roots distal to the section.

The values for conduction velocity obtained in the de-efferented median nerves ranged from $80 \mathrm{~m}$. $/ \mathrm{sec}$. to $105 \mathrm{~m}$. $/ \mathrm{sec}$. (mean $90.6 \pm 9.1 \mathrm{~m}$. $/ \mathrm{sec}$.) in nine recordings, and in the de-efferented ulnar nerves from $81 \mathrm{~m}$. $/ \mathrm{sec}$. to $102 \mathrm{~m}$. $/ \mathrm{sec}$. (mean $89 \cdot 10 \pm 6 \cdot 2$ $\mathrm{m}$./sec.) in eight recordings. There is no significant difference between the mean values obtained for the two nerves. These values, together with the figures for conduction velocity obtained from the intact nerves of the same animals, are summarized in Table II. It will be seen that although there is no significant change in the conduction velocity of the median nerve as a result of de-efferentation, the mean velocity in the ulnar nerve after de-efferentation is less than that in the intact nerve $(P<0.05)$.

TABLE II

CONDUCTION VELOCITY OF AFFERENT FIBRES OF MEDIAN AND ULNAR NERVES

\begin{tabular}{lll} 
& Intact Nerves & De-efferented Nerves \\
\hline Median nerve & $76-100 \mathrm{~m} . / \mathrm{sec} .(8)$ & $80-105 \mathrm{~m} . / \mathrm{sec} .(9)$ \\
& $(89.8 \pm 7 \cdot 4)$ & $(90.6 \pm 9 \cdot 1)$ \\
Ulnar nerve & $90-106 \mathrm{~m} . / \mathrm{sec} .(8)$ & $81-102 \mathrm{~m} . / \mathrm{sec} .(8)$ \\
& $(98.0 \pm 4 \cdot 1)$ & $(89.0 \pm 6 \cdot 2)$
\end{tabular}

Mean figures are given with standard deviations.

Numbers in brackets after range of conduction velocities refer to number of observations.

CONDUCTION VELOCITY IN NERVES FOLLOWING DEAFFERENTATION Ganglionectomies were performed on six animals, but four of these were subsequently excluded from the series. One animal was excluded because of severe damage to the ventral roots, and the other three were excluded because histological studies subsequently showed the ganglionectomy to have been incomplete. In the remaining two animals (baboons $\mathrm{G}$ and $\mathrm{H}$ ), the dorsal root ganglia were excised from segmental levels C5 to T2 and on subsequent histological examination no ganglion cells were seen within $150 \mu$ of the distal end of the excised segment of dorsal root containing the ganglion. Further confirmation that the ganglia had been totally removed was the histological demonstration of complete Wallerian degeneration of the digital nerves.

In both of these animals, degeneration of some efferent fibres had been caused by the operative procedure. This was obvious from the reduction of the amplitude of the muscle action potential recorded in response to maximal stimulation of the medial and ulnar nerves, and it was subsequently confirmed by histological examination of the appropriate 
ventral roots. The damage to the ventral root is thought to be due to interference with its vascular supply (Wray, 1967).

The motor conduction velocity of the fastest conducting fibres of the median and ulnar nerves of the two animals was lower on the partially denervated than on the intact side (Table III), presumably because ventral root damage had caused some loss of fast-conducting fibres.

\section{TABLE III}

CONDUCTION VELOCITY OF EFFERENT FIBRES OF MEDIAN AND ULNAR NERVES

Animal

\begin{tabular}{|c|c|}
\hline Median & \\
\hline $\begin{array}{l}\text { Conduction } \\
\text { Velocity } \\
\text { (m./sec.) }\end{array}$ & $\begin{array}{l}\text { Amplitude } \\
\text { of Action } \\
\text { Potential } \\
(m v)\end{array}$ \\
\hline
\end{tabular}

Ulnar

Conduction Amplitude Velocity of Action (m./sec.) Potential $(m v)$

\begin{tabular}{lrrrrr}
\hline Intact & G & 68.0 & 8.0 & $75 \cdot 3$ & 12.5 \\
nerves & H & 61.5 & $10 \cdot 0$ & $70 \cdot 5$ & $12 \cdot 0$ \\
De-afferented G & G & 57.0 & 3.7 & 69.7 & 6.0 \\
nerves & H & 55.3 & 5.3 & 65.5 & 6.5
\end{tabular}

Conduction velocity and amplitude of action potentials are the mean figures derived from several observations on each animal.

RELATIONSHIP BETWEEN CONDUCTION VELOCITY AND FIBRE DIAMETER Total myelinated fibre counts were made on the de-afferented median and ulnar nerves of the two animals on which complete excision of the dorsal root ganglia had been performed (baboons $\mathrm{G}$ and $\mathrm{H}$ ); on the median and ulnar nerves from both the operated and control sides of the four animals in which ventral root sections had been performed (baboons $\mathrm{M}, \mathrm{N}, \mathrm{V}$, and $\mathrm{T}$ ); and on the median and ulnar nerves from the control side of two other animals (baboons $\mathrm{O}$ and $\mathrm{R}$ ). In some nerves, external diameters of all myelinated fibres of diameter greater than $2 \mu$ were also measured and histograms of the fibre calibre spectrum constructed. The total fibre counts from all the animals are summarized in Table IV from

TABLE IV

TOTAL NUMBER OF MYELINATED FIBRES IN MEDIAN AND ULNAR NERVES

\begin{tabular}{llll} 
& Intact Nerves & $\begin{array}{l}\text { De-efferented } \\
\text { Nerves }\end{array}$ & $\begin{array}{l}\text { De-afferented } \\
\text { Nerves }\end{array}$ \\
\hline Median nerve & $\begin{array}{l}5,360-6,714(9) \\
(\text { mean, 5,860) }\end{array}$ & $\begin{array}{l}4,450-6,308(4) \\
\text { (mean, 5,255) }\end{array}$ & $\begin{array}{l}298-363(2) \\
(\text { mean, 330) }\end{array}$ \\
Ulnar nerve & $\begin{array}{l}5,701-6,904(9) \\
\text { (mean, 6,016) }\end{array}$ & $\begin{array}{l}4,723-5,374(4) \\
\text { (mean, 4,735) }\end{array}$ & $\begin{array}{l}529-934(2) \\
\text { (mean, 731) }\end{array}$
\end{tabular}

Numbers in brackets after range of total numbers of fibres refer to numbers of nerves on which counts were made.

which it can be seen that the number of fibres in the intact nerves ranged from 5,360 to 6,714 in the case of the median nerve, and from 5,701 to 6,904 in the case of the ulnar nerve. Figures for de-efferented nerves were slightly less, ranging from 4,450 to

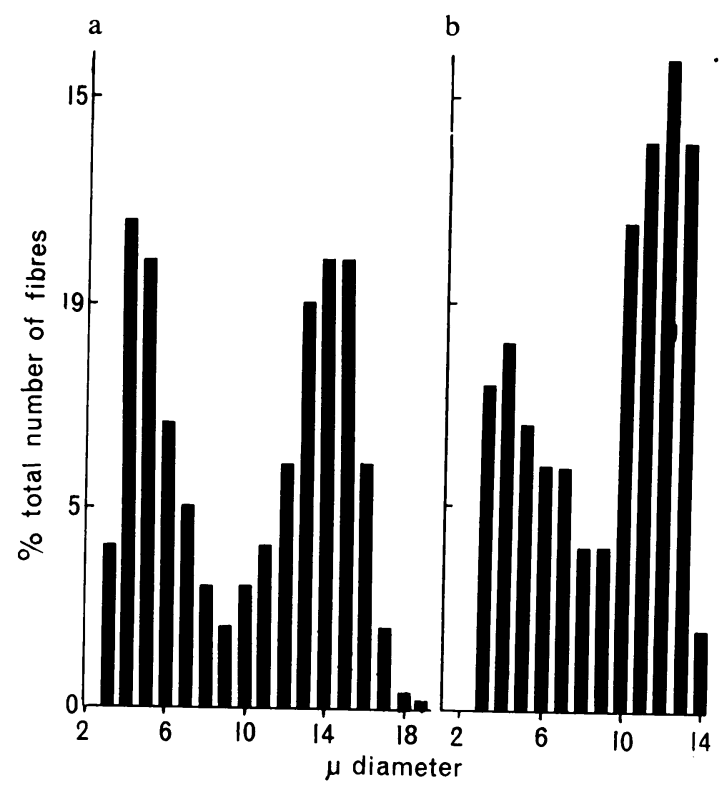

FIG. 4. Fibre calibre spectrum of: (a) intact median nerve; (b) de-afferented median nerve. Baboon $H$.

6,308 for the median nerve, and from 4,723 to 5,374 for the ulnar nerve; there was thus a relatively 2 greater reduction of fibres in the case of the ulnaro nerve. This might be expected from the fact that the ulnar nerve supplies a larger number of hando muscles than the median nerve. The total myelinated fibre counts for the de-afferented median and ulnar 9 nerves are also given in Table IV. These figures underestimate the true number of efferent fibres present in an intact nerve, as substantial damage to the ventral roots during the operative procedure had occurred in both cases (see previous section).

In attempting to relate the conduction velocity of the fastest conducting fibres to the diameter of the largest fibres in the same nerve trunk, the problem arose as to which measurement of fibre diameter to select for comparison with maximal conduction velocity. This difficulty is illustrated by the histograms shown in Figure 4. The largest fibre diameters in the intact median nerve shown in Fig. 4 were $19 \mu$, but there were only 10 such fibres out of a total number of 6,714 . On the other hand in the deafferented median nerve shown in Fig. 4 the largest fibres were $14 \mu$, but there were eight such fibres out of a total number of only 363. In view of the differences in total fibre counts and in the relative proportions of large diameter fibres in intact, deefferented and de-afferented nerves, we have therefore selected the mean diameter of the largest $1 \%$ of fibres in each nerve for correlation with $\frac{1}{c}$ 
TABLE V

RATIO OF CONDUCTION VELOCITY TO FIBRE DIAMETER

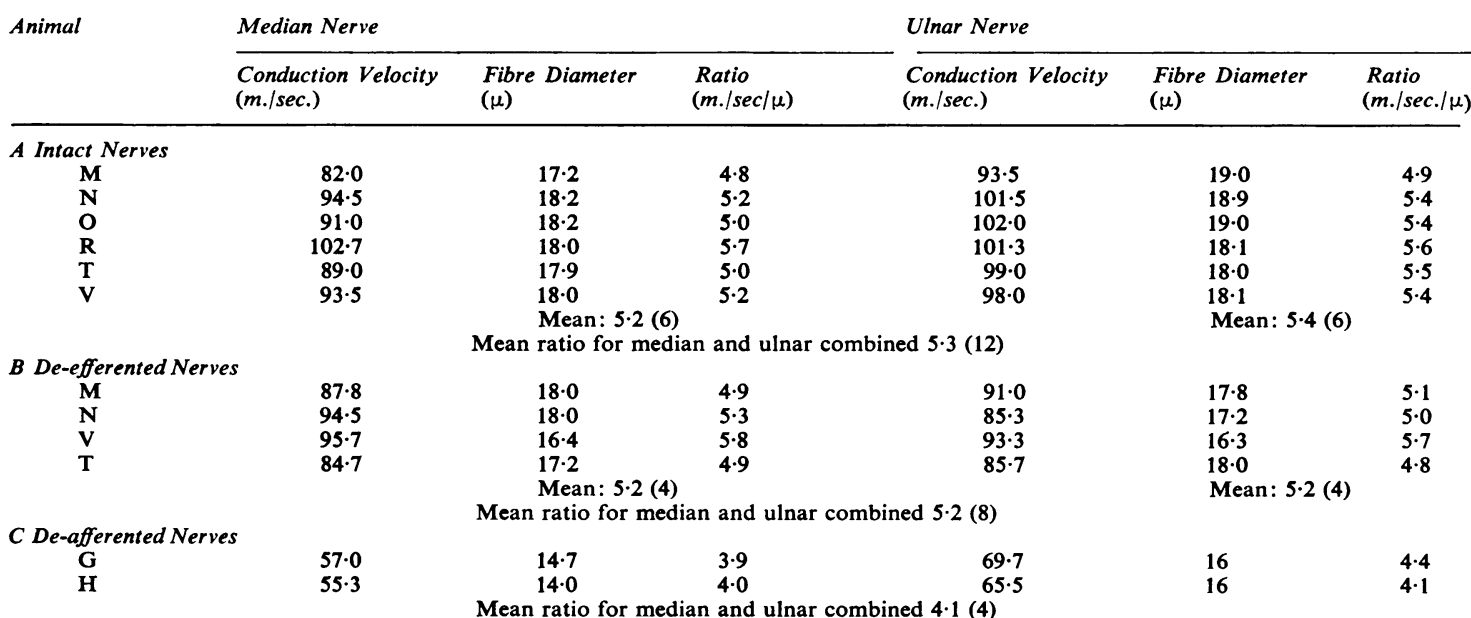

Fibre diameter values represent the mean of the diameters of the larger $1 \%$ of fibres in each nerve. Numbers in brackets after mean figures refer to number of observations.

maximal velocity, rather than taking the diameter of the largest single fibre in the nerve (Hursh, 1939) or the mean diameter of a fixed number of fibres such as 20 in every case (Cragg and Thomas, 1964). A $1 \%$ sample would thus contain 50-70 fibres in the intact nerves, $40-65$ fibres in the de-efferented nerves, and only three to nine fibres in the case of the de-afferented nerves.

The results for 24 nerves in eight animals are summarized in Table $\mathrm{V}$, in which the figures for conduction velocity represent the mean of several observations in each animal. In the case of the intact nerves, the mean ratio of conduction velocity to fibre diameter was $5.3 \mathrm{~m}$./sec. per $\mu$ when the results for median and ulnar nerves were combined. In the case of the de-efferented nerves, the figure obtained for afferent fibres alone was $5 \cdot 2 \mathrm{~m}$./ $/ \mathrm{sec}$. per $\mu$. It can be seen from Table VI that the diameter of the largest fibres in the intact ulnar nerves is significantly greater than that of the largest fibres in the intact median nerves; this may be correlated with the higher conduction velocity of the compound action potential in the ulnar nerve. When efferent fibres alone were considered in the two animals in which de-afferentation was complete, we found that the ratio of conduction velocity to fibre diameter was $4.1 \mathrm{~m} . / \mathrm{sec}$. per $\mu$.

\section{DISCUSSION}

Gasser and Grundfest (1939) and Hursh (1939) showed that the conduction velocity in myelinated fibres was directly proportional to their fibre diameter. This observation was confirmed by Tasaki, Ishii, and Ito (1944), by Berry, Grundfest, and Hinsey (1944) in their study of regenerating nerve fibres, and subsequently by other workers (Adey, 1951; Hodes, 1953). Gasser (1950) demonstrated that a similar relationship also obtained in unmyelinated fibres. Hursh (1939) found that the coefficient which related conduction velocity to fibre diameter in the cat was $6.0 \mathrm{~m}$. $/ \mathrm{sec}$. per $\mu$. He obtained this factor by plotting graphically the conduction velocity of the fastest conducting fibres in a number of different nerves against the diameter of the largest single fibre in each nerve trunk; it seems quite possible, therefore, that only afferent fibres were under consideration, and the factor may not necessarily relate to efferent fibres.

The coefficient of $5.2 \mathrm{~m}$./sec. per $\mu$ calculated in the present study for the largest afferent fibres in the median and ulnar nerves of the baboon is lower than Hursh's figure. In the small number of nerves in which it could be calculated, the coefficient for efferent fibres was lower still $(4 \cdot 1 \mathrm{~m} . / \mathrm{sec} . / \mu)$. In calculating these ratios, we have employed the mean diameter of the largest $1 \%$ of fibres; the ratios would have been even lower if we had taken the diameter of the largest fibre in the transverse section in the manner described by Hursh (1939). The electrophysiological studies in the present investigation were carried out on living, intact animals, and differ in this respect from the experiments of other workers who studied isolated nerves in vitro (e.g. 
Hursh, 1939; Berry et al., 1944; Cragg and Thomas, 1964). In order to obtain comparable results we took special precautions to maintain a uniform temperature of the forearm at 37 to $39^{\circ} \mathrm{C}$.

It was unfortunate that it did not prove possible to excise the dorsal root ganglia completely without causing substantial damage to the underlying ventral roots, since we were therefore unable to determine the diameters and the conduction velocities of the largest efferent fibres in the median and ulnar nerves. The possibility must also be considered that in sectioning ventral roots, occasional damage to the dorsal roots may have resulted, in view of the lower conduction velocities in the de-efferented ulnar nerves than in the intact ulnar nerves. However, no change after de-efferentation was found in the median nerve velocities. Furthermore, histological examination of dorsal roots distal to the ganglia and of digital nerves did not reveal any degenerated fibres.

Boyd (1965) found that the factor relating conduction velocity and fibre diameter was $5 \cdot 7$ $\mathrm{m}$./sec. per $\mu$ for the large motor fibres of the muscle nerves in the cat, but only $4.5 \mathrm{~m}$. $/ \mathrm{sec}$. per $\mu$ for those of the gamma group measured in the same nerves. A considerably lower factor than Hursh's figure of $6.0 \mathrm{~m}$./sec. per $\mu$ has been recently reported by Bessou and Perl (1966) for the afferent fibres of small diameter in the mesenteric nerves of the cat. It therefore seems that the factor relating conduction velocity to fibre diameter is higher in large than in small myelinated fibres. This factor may also vary in different species of animals, since Cragg and Thomas (1964) derived a factor of $4.4 \mathrm{~m}$./sec. per $\mu$ from their study of the fastest conducting fibres in the peroneal nerve of the rabbit. The present work serves to emphasize some of the difficulties encountered in relating conduction velocity to fibre diameter, and confirms that considerable caution must be exercised in employing a standard factor for the purpose (cf Barker, 1962).

The present study indicates that conduction in the afferent fibres of the median and ulnar nerves of the baboon is faster than in man. Mayer (1963) found that the mean conduction velocity of the fastest fibres contributing to the compound action potential was $67.7 \pm 4.4 \mathrm{~m}$. $/ \mathrm{sec}$. for the median nerve and $64.8 \pm 3.8 \mathrm{~m}$./sec. for the ulnar nerve in man. The mean conduction velocities for the same nerves in the baboon were $91.3 \pm 7.2 \mathrm{~m}$./ $/ \mathrm{sec}$. and $98.1 \pm 5.7 \mathrm{~m} . / \mathrm{sec}$. respectively, and the slightly higher conduction velocity in the ulnar nerve may be correlated with the greater diameter of its largest fibres.

The values which have been obtained for motor conduction velocity in the median and ulnar nerves of the baboon are also higher than those from human nerves. Mean figures from six different clinics quoted by Lawrence and Locke (1962) range from 53.0 to $59.1 \mathrm{~m}$./sec. for the median nerve and from 55.1 to $62.4 \mathrm{~m}$./sec. for the ulnar nerve. These may be compared with the mean figure of $72.4 \pm 7.5 \mathrm{~m}$. $/ \mathrm{sec}$. for the median nerve and of $76.5 \pm 5.1 \mathrm{~m}$. $/ \mathrm{sec}$. for the ulnar nerve, obtained in the present work.

The lower conduction velocity in the human nerves may be partly explained by the fact that the observations were made at limb temperatures which were lower by 3 to $4^{\circ} \mathrm{C}$. in man than in the baboon. However, the difference in temperature is not sufficient to account for the discrepancy in conduction velocity which is as much as $20-30 \mathrm{~m}$./sec. It is possible that the factor relating conduction velocity to fibre diameter is lower in man than in the baboon, but until the factor is calculated directly on human nerves this matter remains speculative. If the factors are approximately the same for the two species it follows that the diameter of the largest fibres must be smaller in the median and ulnar nerves of man than in those of the baboon. Unfortunately, it is not possible to draw any firm conclusions on this point from the few published observations on the histology of these nerves in man (Ranson, Droegemueller, Davenport, and Fisher, 1935; Thomas and Fullerton, 1963).

In view of the marked difference which we have found in conduction velocity between the afferent and efferent fibres in the median and ulnar nerves of the baboon it is of interest that Eccles et al. (1966) found only slight differences in conduction between $\overrightarrow{0} \cdot \vec{\varphi}$ afferent and efferent fibres in the nerve to the extensor? digitorum communis muscle of this animal. Further studies of other peripheral nerves of the baboon are clearly required.

\section{SUMMARY}

Conduction velocity was determined and measurements of the total number and diameter of myelinated fibres were made in the median and ulnar nerves of 11 adult baboons. In six of these animals dorsal root ganglia were excised on one side between the levels of the fifth cervical and second thoracic segments in order to produce de-afferentation of the forearm and hand muscles; in four animals ventral root sections were carried out at these levels in order to produce de-efferentation.

In the control median nerves, the conduction velocity of the fastest conducting motor fibres to the abductor pollicis brevis muscle ranged ftom 60 to $84 \mathrm{~m} . / \mathrm{sec}$. (mean $72.4 \pm 7.5 \mathrm{~m} . / \mathrm{sec}$.) and the conduction velocity of the fastest conducting fibres in the whole nerve trunk ranged from 76 to 103 $\mathrm{m}$. $/ \mathrm{sec}$. (mean $91.3 \pm 7.2 \mathrm{~m}$. $/ \mathrm{sec}$.). In the case of the 
control ulnar nerves, the conduction velocity of the fastest conducting motor fibres to the abductor digiti minimi and first dorsal interosseous muscles ranged from 69 to $86 \mathrm{~m}$./sec. (mean $76.5 \pm 5 \cdot 1$ $\mathrm{m}$./sec.) and the conduction velocity of the fastest conducting fibres in the whole nerve trunk ranged from 90 to $111 \mathrm{~m}$. $/ \mathrm{sec}$. (mean $98.1 \pm 5.7 \mathrm{~m}$. $/ \mathrm{sec}$.). It is concluded that in these two nerves in the baboon, afferent fibres conduct at a greater velocity than efferent fibres.

In the animals on which ventral root sections had been performed, the conduction velocity of the fastest conducting afferent fibres was related to the mean diameter of the largest $1 \%$ of myelinated fibres in each nerve. The mean ratio of conduction velocity to fibre diameter in the eight completely deefferented nerves was $5.2 \mathrm{~m}$./sec. per $\mu$; the mean ratio for 12 control nerves was $5 \cdot 3 \mathrm{~m}$./sec. per $\mu$. Excision of dorsal root ganglia produced complete de-afferentation in the median and ulnar nerves of only two animals, and as a result of unavoidable damage to the underlying ventral roots also caused a substantial loss of efferent fibres. The mean ratio of conduction velocity to fibre diameter for the fastest conducting efferent fibres which remained was $4.1 \mathrm{~m}$. $/ \mathrm{sec}$. per $\mu$.

The results are discussed and the conduction velocities compared with those in the median and ulnar nerves of man.

We wish to thank Professor Gilliatt for his very helpful criticism and advice, Miss C. Botwright and Mr. W. Hinkes for their technical assistance, and Miss $\mathbf{M}$. Jenkyns for typing the script. The work was carried out during the tenure by J. G. McLeod of a Nuffield Foundation Dominion travelling fellowship. A personal grant to S. H. Wray from the Medical Research Council is gratefully acknowledged. We also thank the Polio Research Fund for their support of the work.

\section{REFERENCES}

Adey, W. R. (1951). The nervous system of the earthworm megascolex. J. comp. Neurol., 94, 57-93.

Barker, D. (Editor) (1962). Discussion. In Symposium on Muscle Receptors, p. 275, University Press, Hong Kong.

Berry, C. M., Grundfest, H., and Hinsey, J. C. (1944). The electrical activity of regenerating nerves in the cat. J. Neurophysiol., 7, 103-115.
Bessou, P., and Perl, E. R. (1966). A movement receptor of the small intestine. J. Physiol. (Lond.), 182, 404-426.

Boyd, I. A. (1965). Differences in the diameter and conduction velocity of motor and fusimotor fibres in nerves to different muscles in the hind limb of the cat. In Studies in Physiology, edited by D. R. Curtis, and A. K. McIntyre, pp. 7-12. Springer, Berlin, and Heidelberg.

Cragg, B. G., and Thomas, P. K. (1964). The conduction velocity of regenerated peripheral nerve fibres. J. Physiol. (Lond.), 171, 164-175.

Donaldson, H. H., and Hoke, G. W. (1905). On the areas of axis cylinder and medullary sheath as seen in cross sections of the spinal nerves of vertebrates. $J$. comp. Neurol., 15, 1-16.

Duncan, D. (1934). A determination of the number of nerve fibers in the eighth thoracic and the largest lumbar ventral roots of the albino rat. Ibid., 59, 47-60.

Eccles, R. M., Phillips. C. G., and Chien-Ping, W. (1966). The innervation of $\mathrm{m}$. extensor digitorum communis of the baboon's forearm. J. Physiol. (Lond.), 185, 25-26 P.

Espir, M. L. E., and Harding, D. T. C. (1961). Apparatus for measuring and counting myelinated nerve fibres. J. Neurol. Neurosurg. Psychiat., 24, 287-290.

Gasser, H. S. (1950). Unmedullated fibers originating in dorsal root ganglia. J. gen. Physiol., 33, 651-690.

- and Grundfest, H. (1939). Axon diameters in relation to the spike dimensions and the conduction velocity in mammalian A fibers. Amer. J. Physiol., 127, 393-414.

Gutmann, E., and Sanders, F. K. (1943). Recovery of fibre numbers and diameters in the regeneration of peripheral nerves. $J$. Physiol. (Lond.), 101, 489-518.

Hodes, R. (1953). Linear relationship between fiber diameter and velocity of conduction in giant axon of squid. J. Neurophysiol., $16,145-154$

Hursh, J. B. (1949). Conduction velocity and diameter of nerve fibers. Amer. J. Physiol., 127, 131-139.

Lawrence, D. G., and Locke, S. (1962). Motor nerve conduction velocity in diabetes. Arch. Neurol. (Chic.), 7, 365-367.

Mayer, R. F. (1963). Nerve conduction studies in man. Neurology (Minneap.), 13, 1021-1030.

Ranson, S. W., Droegemueller, W. H., Davenport, H. K., and Fisher, C. (1935). Number, size and myelination of the sensory fibres in the cerebrospinal nerves. Res. Publ. Ass. nerv. ment. Dis., 15, 3-34.

Sanders, F. K. (1948). The thickness of the myelin sheaths of normal and regenerating peripheral nerve fibres. Proc. roy. Soc. B., 135, 323-357.

Sherrington, C. S. (1894). On the anatomical constitution of nerves of skeletal muscles; with remarks on recurrent fibres in the ventral spinal nerve-root. J. Physiol. (Lond.), 17, 211-258.

Tasaki, I., Ishii, K., and Ito, H. (1944). On the relation between the conduction rate, the fibre diameter and the internodal distance of the medullated nerve fibre. Jap. J. med. Sci., Pt. III Biophysics, 9, 189-199.

Thomas, P. K., and Fullerton, P. M. (1963). Nerve fibre size in the carpal tunnel syndrome. J. Neurol. Neurosurg. Psychiat., 26, 520-527.

Williams, P. L., and Landon, D. N. (1963). Paranodal apparatus of peripheral myelinated nerve fibres of mammals. Nature (Lond.), 198, 670-673.

Wray, S. H. (1967). Anatomical studies on certain muscle nerves of primates. Thesis to be submitted for the degree of Ph.D. in the University of London. 